\title{
PMSE long term observations using SuperDARN SANAE HF radar measurements
}

\author{
Olakunle Ogunjobi ${ }^{1,2, *}$, Venkataraman Sivakumar ${ }^{2}$, Judy Ann Elizabeth Stephenson ${ }^{2}$, and \\ Zolile Mtumela ${ }^{2}$
}

${ }^{1}$ Center for Space Research, School for Physical and Chemical Sciences, North-West University, Potchefstroom, South Africa ${ }^{2}$ School of Chemistry and Physics, University of KwaZulu-Natal, Durban, South Africa

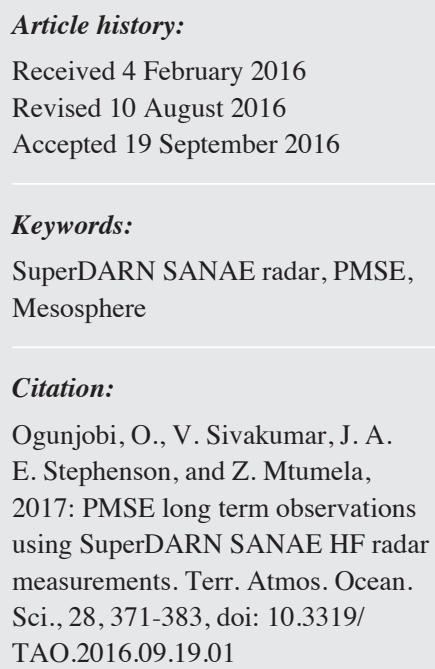

\begin{abstract}
It is known that the presence of nanometre-scale ice particles and neutral air turbulence in the Polar summer mesosphere modify the D-region plasma, resulting in strong backscatter. These strong backscatters are referred to as Polar Mesosphere Summer Echoes (PMSE). Although studies on PMSE have been ongoing for over three decades, aspects revealed by various instruments are still the subject of discussion. As a sequel to the paper by Ogunjobi et al. (2015), we report on the long term trends and variations in PMSE occurrence probability from Super Dual Auroral Radar Network (SuperDARN) high frequency (HF) radar measurements over the South African National Antarctic Expedition IV (SANAE IV). In this current paper, a simple multiple-filter technique is employed to obtain the occurrence probability rate for SuperDARN-PMSE during the summer periods for the years 1998 - 2007. The SuperDARN-PMSE occurrence probability rate in relation to geomagnetic activity is examined. The mesospheric neutral winds and temperature trends during these periods, are further studied and presented in this paper. Both the monthly and diurnal variations in occurrence are consistent with previous reports, confirming the presence of PMSE from SuperDARN SANAE IV radar measurements and the influence of pole to pole mesospheric transport circulation. The special mesospheric mean flow observed prior to the year 2002 is ascribed to the influence of solar activity. The SuperDARN-PMSE occurrence probability peaks with lowered geomagnetic activity. These present results support the hypothesis that the particle precipitation also plays an important role in SuperDARN-PMSE occurrence.
\end{abstract}

\section{INTRODUCTION}

It has been known that from November to February in the southern hemisphere, lower temperatures $(<130 \mathrm{~K}$, Lübken et al. 2004) are usually found at polar latitudes mesopause (about $90-100 \mathrm{~km}$ altitudes). This enables the charging ice particles from water vapor to grow at mesopause. The interactions of these charged ice particles and mesospheric air turbulence, initiated by propagating gravity waves, results in strong radar backscatter echoes (bragg's scattering) in the high-latitude summer mesosphere (Rapp and Lübken 2004). Ecklund and Balsley (1981) earlier refereed such strong radar echoes as Polar Mesosphere Sum-

\footnotetext{
* Corresponding author

E-mail: olakunle.ukzn@gmail.com
}

mer Echoes (PMSE). In the past few years, the PMSE have been closely linked to visible ice particles below $90 \mathrm{~km}$ altitude, known as Noctilucent Clouds (NLC) (Cho and Röttger 1997; Rapp and Lübken 2004; Smirnova et al. 2010). Prequel to this paper, (Ogunjobi et al. 2015), we describe how the NLC and PMSE arise from the ice particle growth in an extremely low Polar summer mesospheric temperature periods. Both NLC and PMSE are good indicators (or suspected indicators) of anthropogenic global warming. Due to the NLC measurement (which is strongly dependent on observer and weather conditions) limitations, PMSE has been a plausible candidate. This is because PMSE observations with radar have the advantage of being continuous.

Since 1981 researchers observed several PMSE aspects using different instrument techniques. This ranges from 
ground based radars to space based instruments (Ecklund and Balsley 1981; Kirkwood 1993; Palmer et al. 1996; Hoffmann et al. 1999; Rapp and Lübken 2004; Klekociuk et al. 2008). However, PMSE observations from space are datastarved, leading to huge gaps in the ability to understand all of the contributing processes. This is particularly true for the southern hemisphere, which often lacks both space and ground based observational data. There is a growing effort to complement PMSE observations with coherent high frequency (HF) Super Dual Auroral Radar Network (SuperDARN) (e.g., Ogawa et al. 2004; Hosokawa et al. 2005; Liu et al. 2013; Ogunjobi et al. 2015). Using data from Syowa East HF radar in the Antarctic (during 1999/2000 and 2000/2001 summers) and Iceland HF radar in the Arctic (1999 and 2000 summers), Hosokawa et al. (2005) observed a predominant diurnal PMSE variation, similar to Ogunjobi et al. (2015) observations, and a weaker PMSE interhemispheric asymmetry occurrence than those earlier reported results. Even so, they noticed possible contamination from ionospheric Eregion echoes. Attempts have been made to eliminate such contamination and reported in the literature. Liu et al. (2013) extracted PMSE from SuperDARN Zhongshan HF radar in Antarctica (2010 - 2012 summer) when $\mathrm{Kp} \leq 1$. In keen contrast to Hosokawa et al. (2005), Liu et al. (2013) found a semidiurnal Variation in PMSE. This special diurnal characteristics of PMSE from the Zhongshan was hypothesised to be the influence of auroral particle precipitation.

Based on this hypothesis, we have expanded our observations in this present study to cover at least a complete solar cycle phase. Here, we have analysed PMSE observations during maximum and minimum phases of solar cycle to add valuable insights in this field.

This paper presents long term PMSE observations with SuperDARN South African National Antarctic Expedition IV (SANAE IV) $\left(71.68^{\circ} \mathrm{S}, 2.85^{\circ} \mathrm{W}\right) \mathrm{HF}$ radar (hereafter referred as SuperDARN-PMSE) over the period 1998 - 2007. The monthly, diurnal, and interannual characteristics of SuperDARN-PMSE are determined and presented in the results and analysis section. We examined the SuperDARNPMSE occurrence rate in relation to geomagnetic activity and mesospheric wind flow measured by meteor radar. To confirm our previous suggestion on temperature variations, the temperature changes in relation to SuperDARN-PMSE have been further expanded.

\section{INSTRUMENTATION AND DATA ANALYSIS}

\subsection{SuperDARN SANAE IV Radar}

Data from the SuperDARN SANAE IV radar is employed in this study. The antenna array consists of 16 antennae operated as a phased array having $170^{\circ}$ bore site. The radar uses approximately $12 \mathrm{MHz}$ frequency. SANAE IV radar is technically and operationally similar to the 32 other SuperDARN radars located at polar and mid latitudes
(Greenwald et al. 1995; Lester 2013). The SuperDARN radars at different locations operate on a common configuration for half of the daily operational time (Greenwald et al. 1995; Hosokawa et al. 2005; Lester 2013). During the common operational time, different SuperDARN radars are intercalibrated so that a backscattered power for one system can be quantitatively compared to any of the other radars. For instance, Villain et al. (2002) performed a statistical study of the Doppler spectral width of high-latitude F-region ionospheric echoes using six SuperDARN HF radars (Saskatoon, Goose bay, Kapuskasing, Thykkvibaer, Stokkseyri, and Hankasalami). For half of SuperDARN radars operational time, an internal consistency is usually maintained, using common parameters. During the remaining half of the SuperDARN HF radar observational time, parameters for individual radar is discretionary.

Only common mode Program data were selected for this analysis. During common time measurements, the SuperDARN radars are sequentially scanned from beam 0 to beam 15 across its total 75 slant range gates with a step in azimuth variation of $3.33^{\circ}$, a scan repeat time of $\sim 2 \mathrm{~min}$, a range resolution of $45 \mathrm{~km}$, and a peak power of about $10 \mathrm{~kW}$. The beams have maximum sensitivity at elevation angles of $\leq 35^{\circ}$ to allow backscatter echo detection. The return echoes for each beam are integrated over 3 or $7 \mathrm{~s}$. Figure 1 shows the geographic field of view (FOV) of SANAE IV HF radar superimposed on geomagnetic coordinates, indicating the area covered by the entire radar beams (blue vertical lines). It is apparent that the radar is located near the auroral location in the Antarctic region. The SuperDARN radar aspect sensitivity along auroral locations has been discussed in the

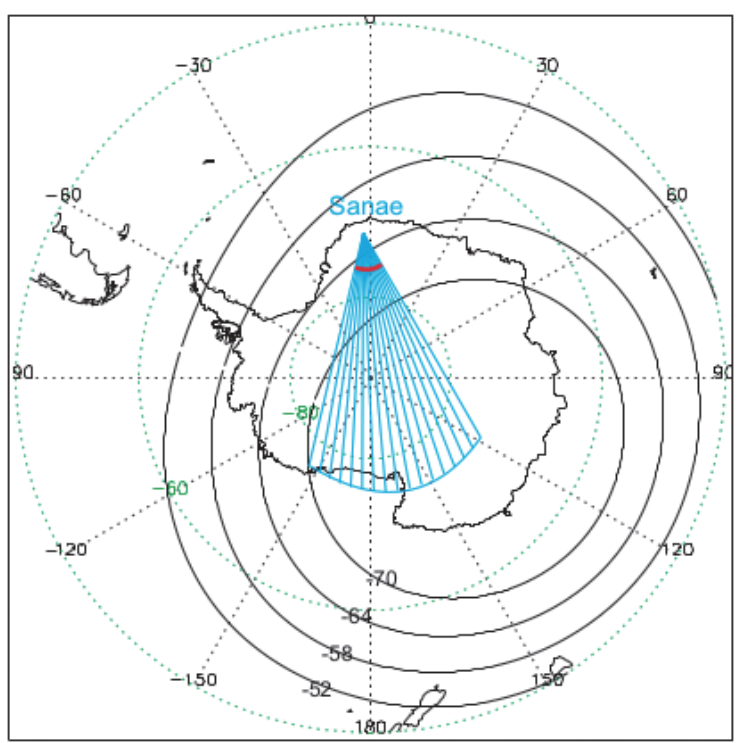

Fig. 1. Maps showing the geographic coordinate (green-dotted lines) of SANAE radar fields of view superimposed on a geomagnetic coordinate (thick line) in the Antarctic. The expected region of SANAE PMSE is shaded in red. (Color online only) 
study of Liu et al. (2013). The shaded portion (red) indicates the probable PMSE observation region based on the SANAE IV radar aspect sensitivity. For clarity, the FOV indicates that E-region echoes can be detected using the SANAE SuperDARN HF radar when the FOV intersects an auroral electrojet region.

It should be noted that the backscatter delays at slant range gate 0 is set to $1200 \mu$ s interpulse period (length), which is equivalent to $180 \mathrm{~km}$ [i.e, within the MLT (Mesosphere and Lower-Thermosphere) region]. The subsequent pulse length is set to $300 \mu \mathrm{s}$, equivalent to a length of $45 \mathrm{~km}$. The oblique sounding technique of SuperDARN radar is such that it can detect coherent backscatters at higher altitudes. At ionospheric E-region altitudes, plasma instabilities can be detected simultaneously, due to the location of SANAE HF radar. Some of the proven overlapping plasma instabilities at PMSE height, however, include field aligned irregularities in the ionospheric E-region (sporadic E-region, $\mathrm{E}_{\mathrm{s}}$, echoes) and meteor trail.

\subsection{The Event}

A systematic approach is needed to isolate a PMSE event from other overlapping or contaminating echoes. The data are processed using the multiple-filter approach in the following way:

(1) Eliminates $\mathrm{E}_{\mathrm{s}}$ echoes (above $180 \mathrm{~km}$ ). This is to limit the influx of strong echoes due to field aligned irregularities where the angle between ambient geomagnetic field vectors and radar waves is about $90^{\circ}$, the so-called geomagnetic aspect condition. See Liu et al. (2013) on SuperDARN radar aspect sensitivity. Auroral E-region echo is removed by limiting spectral width and Doppler shift below $50 \mathrm{~m} \mathrm{~s}^{-1}$. This will allow extraction of only the inbound radial velocities as expected for PMSE with a shorter wavelength than that of the emitted pulse (Villain et al. 2002).

(2) Meteor trail is removed by limiting the signal-to-noise ratios to above $6 \mathrm{~dB}$. According to Ogawa et al. (2004), meteors are normally short-lived events $(<120 \mathrm{~s}$ scan time of SuperDARN radar) with $<6 \mathrm{~dB}$ signal-to-noise ratios.

(3) The above conditions apply for all $0-15$ beams. This condition is used as a further measure to avoid spurious events, especially, the expected few strong echoes due to field aligned irregularities from western-most and eastern-most beams.

Figure 2 describes the typical example of these backscatter features (power, width, and velocity) observed for 21 December and April 2005, demonstrating the PMSE disturbances in the signal returns from radar. During the summer solstice (Fig. 2 left), backscatters return are seen to be higher in comparison to 21 April 2005 (Fig. 2 right). This is different from the sequel paper in which observation is

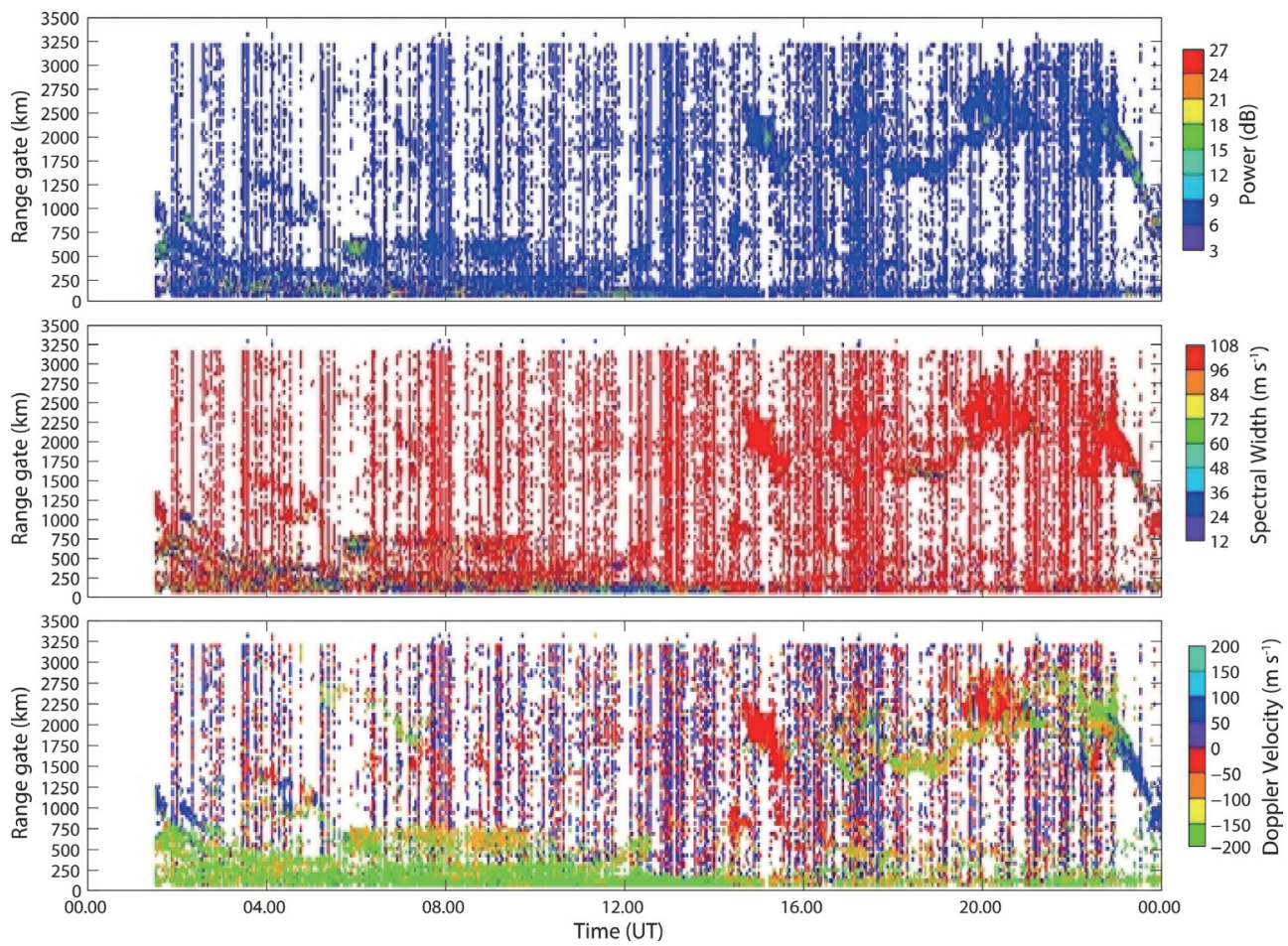

Fig. 2. Range-time color map of observed SuperDARN SANAE IV radar backscatter power, spectral width and Doppler velocity. The figure illustrates for beam 12 near range gates on 21 December 2005. At 12:00 UT, PMSE occurrence is apparent at gate 0; Power is $>15 \mathrm{~dB}$, Width $<36 \mathrm{~m} \mathrm{~s}^{-1}$, and Doppler velocity $=-200 \mathrm{~m} \mathrm{~s}^{-1}$. (Color online only) 
limited to the near gates.

Figure 2 shows the range and time plot from beam 12. The altitude range where PMSE might be reasonably expected to occur, which is the altitude range with super saturation with respect to ice, is within the first range gate. Figure 2 also illustrates the typical example of all backscatter features (power, width, and velocity) showing the characteristics of other contaminating echoes as observed for 21 December. During the summer solstice on 21 December 2005, backscatter returns are seen to be larger at higher range gate. This is different from the sequel paper (Ogunjobi et al. 2015, Fig. 2), in which observation is limited to the near gate. Here it is apparent that echoes observed by SuperDARN radar are beyond $180 \mathrm{~km}$. In this context, it should also be noted that the main problem with the SuperDARN observations is their oblique viewing geometry and their very long range gates with a length of $45 \mathrm{~km}$. Hence, the observations do not allow a direct verification of where the observed echoes originated from. However, the aforementioned multiple-filter algorithm enables us to isolate and analysed the PMSE occurrence probability, which will be discussed subsequently. From many independent observations (satellite and ground based) over Antarctica (e.g., Hervig et al. 2009), it has been established that the PMSE season starts around mid-November and ceases in the end of February.

\subsubsection{SuperDARN Neutral Wind Data}

In addition to backscatters detection, SuperDARN observation of meteor trails within E-region $(90-95 \mathrm{~km})$ is associated with drift in neutral wind velocities which allows for studying the trends of meridional and zonal winds in relation to SuperDARN-PMSE season. A detailed description of neutral winds tracking using SuperDARN radar can be found elsewhere (Hussey et al. 2000; Chisham et al. 2007). Hussey et al. (2000), for example, found a good agreement between neutral wind measurements from SuperDARN radar and medium frequency (MF) radar at an altitude of about $95 \mathrm{~km}$. The advantage of MF radar wind observations are its good altitude resolution. Note, that winds are altitude dependent and thus meteor radar observations of neutral winds may only be relative and not high in altitude accuracy (Yukimatu and Tsutsumi 2002, 2003).

\subsection{TIMED/SABER}

The TIMED/SABER (Thermosphere Ionosphere Mesosphere Energetic and Dynamics / Sounding of the Atmosphere using Broadband Emission Radiometry) satellite was launched on 7 December 2001 into a $625 \mathrm{~km}$ circular orbit, with $74.1^{\circ}$ inclination. The orbit period of TIMED/SABER is $102 \mathrm{~min}$. SABER is measuring $\mathrm{CO}_{2} 15 \mu \mathrm{m}$ limb emission, which can be used to estimate the neutral temperatures up to approximately $130 \mathrm{~km}$. In order to maintain a certain temperature in the instrument, SABER obtains profiles from $83^{\circ} \mathrm{S}$ to $52^{\circ} \mathrm{N}$ every 60 days and then switches to an analogous direction. Here, we acquire SABER temperature data only when it is over the vicinity of SANAE IV (i.e, $71+/-4^{\circ}$ latitudes and $2+/-10^{\circ}$ longitudes). We have used only possible periods of SABER temperature measurements for the year 2002/2003, 2003/2004, 2004/2005, 2005/2006, and 2006/2007 summers. This, at least, covers the minimum phase of solar cycle period under study.

\section{OBSERVATIONS AND ANALYSIS}

\subsection{Diurnal Variation}

Using SuperDARN HF radar data set covering about a decade, we examine SuperDARN-PMSE occurrence probability rate, based on the defined conditions. Figure 3 shows these conditions against local time (LT), which are (a) average power, (b) average Doppler velocity, and (c) spectral width of backscatter echoes averaged over the near range gate and at the interval from 1 November to 29 February, for the different years. Recall that these aforementioned parameters are conditions that define the SuperDARN-PMSE form.

It is evident from the figure that the echo parameters have predominant diurnal variations. We observe peak average power on the local noon and lower on the night sides, as shown in Fig. 3a. The usually low average power observe for 1999/2000 and 2004/2005 summer might be, perhaps, due to data gap that exists during these periods. Generally, the average power for all years have similar behavior and exhibit a broad peak structure with the higher peaks around 11 - 14 LT. Between 10 and 14 LT, the average widths are below $20 \mathrm{~m} \mathrm{~s}^{-1}$ and then increase gradually with LT. The difference in spectral width variation for the different years is not obvious at both noon and night. In the early hours, we observe large spectral widths for echoes, probably as a result of particle precipitation near the aurora oval region (Tsunoda 1988). For spectral width and Doppler velocity (Figs. 3b and c), the local noon variation is deeper than that of the night. The measured Doppler velocities indicate diurnal variations and are mainly negative on the local noon (around $13 \mathrm{LT}$ ) with a value of $-200 \mathrm{~m} \mathrm{~s}^{-1}$, and rise to zero at local midnight (around $22 \mathrm{LT}$ ), which indicates that the radar scatters are moving towards the radar. We found that there is no substantial difference in the diurnal variations of the Doppler velocity for all years; nonetheless, the values of the minima vary significantly between -200 and $0 \mathrm{~m} \mathrm{~s}^{-1}$ and the maxima between -50 and $50 \mathrm{~m} \mathrm{~s}^{-1}$.

The SuperDARN-PMSE occurrence probability rate averaged over the interval from 1 November to 29 February from the SANAE IV HF radar is shown in Fig. 4. Here the data were averaged using an hourly running mean for all years. The diurnal trends in the SuperDARN-PMSE occurrence rate show similar behaviour to those of radar 
backscatter parameters. The occurrence probability rate exhibit diurnal trends for all year and are characterised by maxima as seen almost at the same times as that of radar power and minima almost at the time of minimum spectral widths and Doppler velocities. Note that there are broader maxima from 11 to $13 \mathrm{LT}$ and minima between 20 to 22 LT. The diurnal variation shapes are seen almost every year except 2002/2003 summer when the occurrence probability rate seems to have about 3 hour time lag. Assuming that SuperDARN-PMSE is a Poisson process, the hourly mean intervals from year to year rates should be described using an exponential distribution. Employing the maximum possible occurrence rate to evaluate the Cumulative Distribution Function $(\mathrm{CDF})$, one finds that the probability of changes occurring by chance in the year-to-year SuperDARN-PMSE within an arbitrary 20 min interval is $\mathrm{P}=1.0-2.5$ from year to year.
Similar PMSE diurnal pattern variations were found by very high frequency (VHF) radar observations (Hoffmann et al. 1999; Morris et al. 2005; Latteck et al. 2007; Nilsson et al. 2008). Hosokawa et al. (2005) observed similar diurnal results with Syowa and Iceland HF radar too. Also, a fitted diurnal model of PMSE variation by Klostermeyer (1999) show that, the contribution from solar ionisation and particle precipitation to diurnal variation of PMSE reflectivity is high. At high-latitudes, the ionisation of the MLT is mainly ascribable to the Lyman $\alpha$ radiation (Brekke 1997) and precipitation of magnetospheric particles (for instance, De Abreu et al. 2010; Ogunjobi et al. 2014a, b). The $\alpha$ radiation can cause enhanced ionisation at the noon while the precipitation has a minimum at dawn (Codrescu et al. 1997). Thus, a superposition of both ionisation sources might be a likely explanation for SuperDARN-PMSE diurnal variations. A one-step way to ascertain this is by studying the
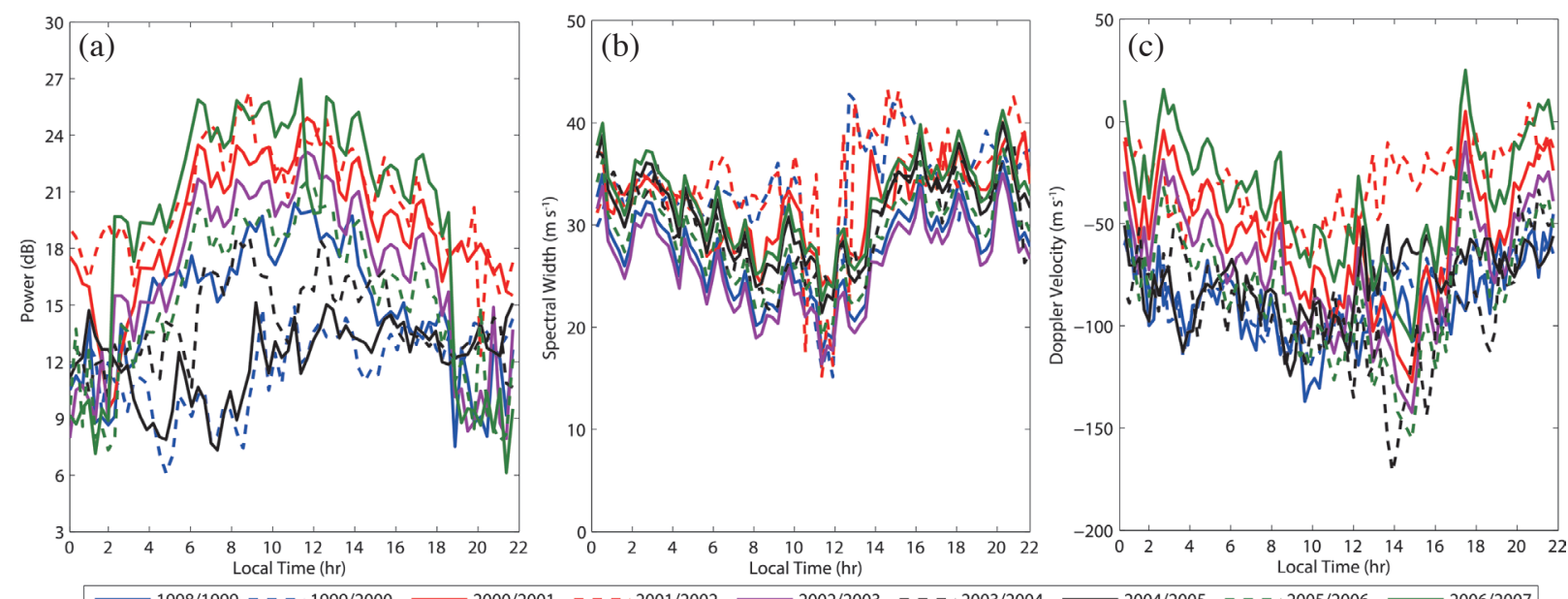

Fig. 3. Diurnal variations of (a) average power, (b) average spectral width, and (c) average Doppler velocity at slant range gate 0 - 1 from 1998 2007. (Color online only)

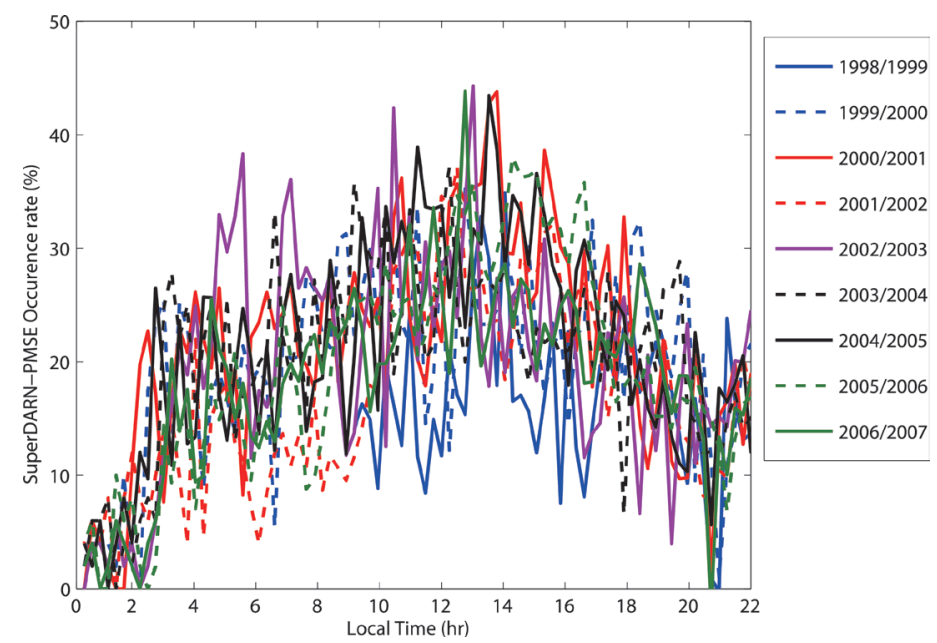

Fig. 4. Averaged diurnal variations of SuperDARN-PMSE occurrence rate from the years 1998 - 2007. (Color online only) 
geomagnetic activity dependence of SuperDARN-PMSE, details of which is presented later (section 3.3). Nevertheless, there are some discrepancies in the maximum and minimum occurrence temporal positions due to different conditions and criteria such as power, width and velocity being employed for analysis in this study. Another plausible reasons for temporal discrepancies might be the small changes in the shape of the diurnal variations from year to year.

Although, Liu et al. (2013) observed primary maximum PMSE occurrence near 0 LT and a secondary maximum near 13 LT while a distinct minimum was near $19 \mathrm{LT}$. Balsley et al. (1983) had earlier reported that the PMSE occurrence has a broad maximum at $1-2$ hour after the local noon and that of the secondary peak usually appears around the local midnight.

The major cause of diurnal and semidiurnal PMSE occurrence is not yet completely understood. Several factors can affect the PMSE intensity, which includes electron density (Kirkwood 1993), 3 hr-shifted meridional winds (Hoffmann et al. 1999), temperature (Klostermeyer 1999), planetary waves (Klekociuk et al. 2008), and energetic particle precipitation (Liu et al. 2013). Nonetheless, it is clear to note that these factors are complex and have different contributions.

\subsection{Combined Monthly Variation}

The monthly average of the echoes parameters from the near range gate can be compared with SuperDARN-PMSE rates. Therefore, we have combined the radar power, velocity and width measurements over the years 1998 - 2007 and grouped in terms of months (from January to December). Figure 5 shows mean monthly variations of: (a) average power, (b) average Doppler velocity, and (c) average spectral widths.

It is evident from the Fig. 5a that, the combined average power is higher during the Antarctic summer solstice, which might probably be as a result of smaller backscatter population owing to the solar radiation in summer. In Fig. 5b, we observe the high-level velocity around late February and gradual decrease towards late November. The echoes Spectral widths are lesser around summer solstice as shown in Fig. 5c.

Based on the monthly average of the parameters, we examine the start and end periods of SuperDARN-PMSE peaks. The inter annual variations in the SuperDARNPMSE occurrence probability rate observed by SANAE IV HF radar during Antarctic summers of the years from 1998 - 2007 are examined. To eliminate the influence of frequent data gap, the data (during common mode) are averaged with a running mean over 2 days.

It can be seen in Fig. 6 that the highest peaks are shifted towards the summer solstice, suggesting that in the majority of cases, the SuperDARN-PMSE follows the initial condi- tions of Power, Doppler velocity and spectral width. The SuperDARN-PMSE suddenly peak in early December, maximise around December solstice, stay at the highest level of about $50 \%$ to the early part of January and then decrease gradually to the end of February every year. Apparently, the increasing rates of SuperDARN-PMSE at higher power is attenuated towards the beginning of winter by larger spectral width. Through the observational periods, there were no significant changes in the SuperDARN-PMSE occurrence rate trend.

These monthly variations are in agreement with other PMSE observations from VHF radars Bremer et al. (2009), for example, despite the difference in radar locations and experimental setup. These results also agree with previous PMSE observations with other radars despite the differences in location and time. Using the SuperDARN HF radar, Hosokawa et al. (2005) found that the PMSE occurrence at Syowa (1999 - 2000 and 2000 - 2001) and Iceland (1999 and 2000) shows a sudden increase in the beginning of the summer, maximises days after the summer solstice, and a gradual decay to the end of January. Similarly, Liu et al. (2013) found an enhancement of PMSE intensity around the summer solstice using Zhongshan HF radar in Antarctica during $2010-2012$.
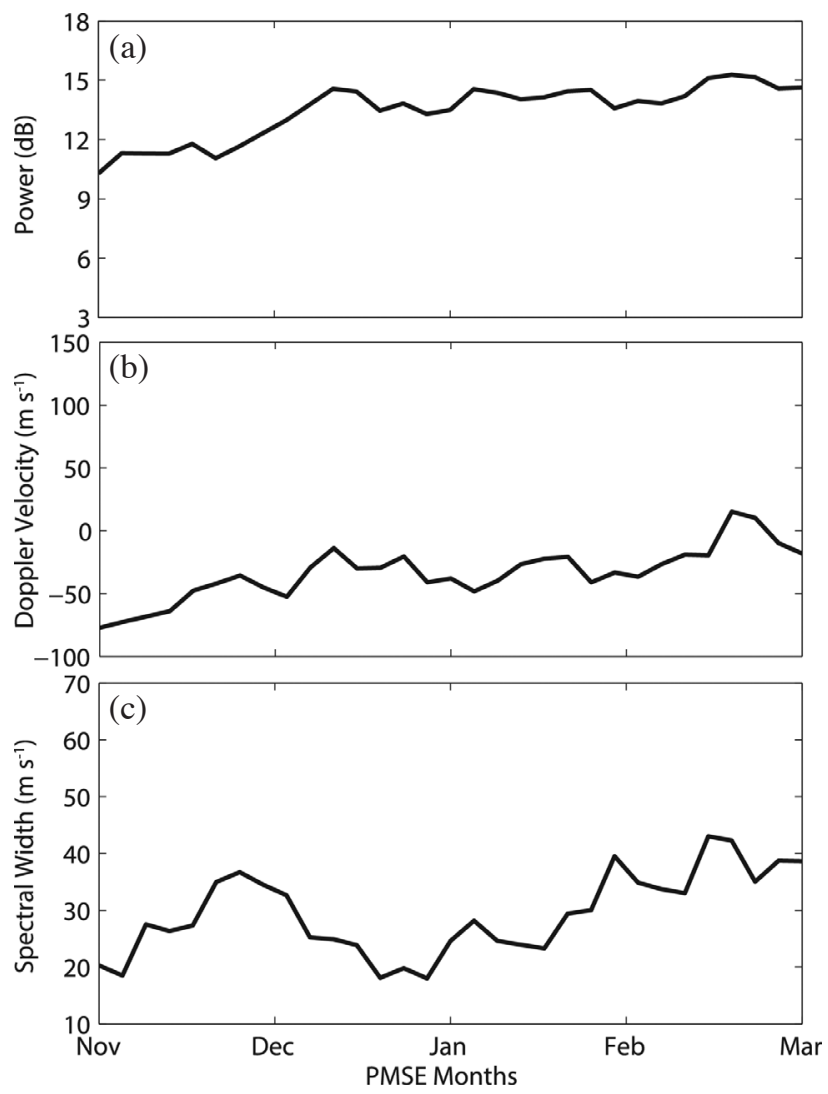

Fig. 5. Combined Monthly variation of (a) average power, (b) average spectral width, and (c) average Doppler velocity at slant range gate 0 - 1 from the years $1998-2007$. 

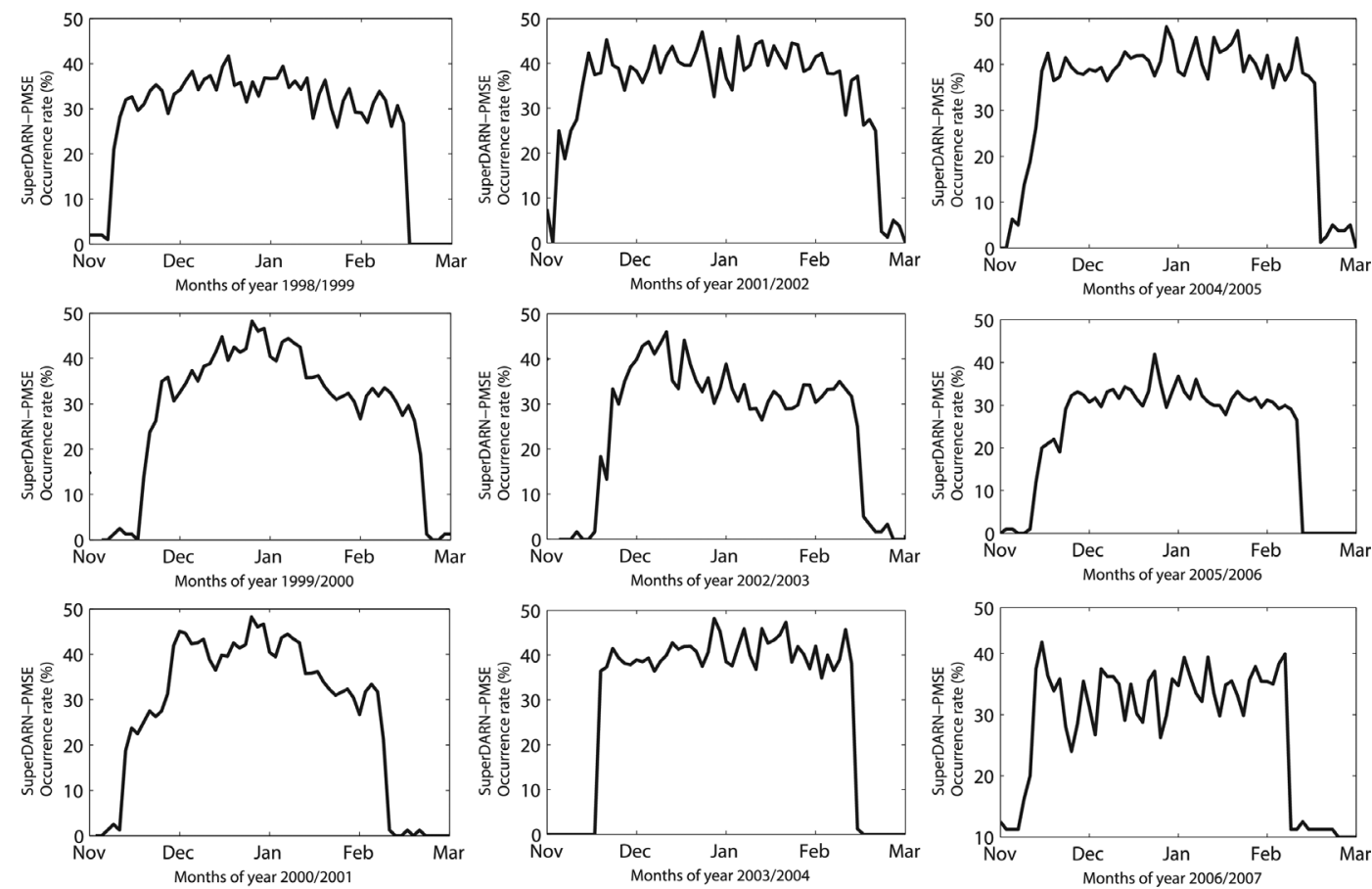

Fig. 6. Inter annual variations of SuperDARN-PMSE occurrence rate from the years 1998 - 2007. The data were averaged using a running mean over 2 days for time interval from October until February.

\subsection{Superdarn-PMSE Occurrence in Relation to Geomagnetic Activity}

As noted above in section 3.1, some radar observations not only examined the geomagnetic activity dependence of backscatter echoes, but also the physics of the mechanisms involved. In order to examine a possible connection between SuperDARN-PMSE and geomagnetic activity, we present the combine diurnal and monthly variations in SuperDARNPMSE occurrence rate at different geomagnetic activity levels, using $\mathrm{Kp}$ index as proxy. The $\mathrm{Kp}$ is a measure of the strength of the solar wind driving the magnetosphere. The monthly average Kp index from the OMNI website (http:// omniweb.gsfc.nasa.gov) illustrates the average level of geomagnetic activities from the years 1998 - 2007 as shown in Fig. 7. On average, the level of Kp index varies for different years. However, the central tendency (mean) measure application provides us with, at least, a qualitative information regarding how it varies from year to year. The year 2003 appears to be the time of enhanced activities, with average $\mathrm{Kp}=3$ for several months, while in other years $\mathrm{Kp}$ is in the average of $<3$. With the influence of solar cycle, one can assume that the yearly variation might not, necessarily, separate into distinct categories when considering the higher activity of the year 2003. Kp seems to be generally high during the summer months, particularly November and December periods.

For clarity, however, the $\mathrm{Kp}$ values are grouped into three thresholds; $\mathrm{Kp}=0$ (quite time), $\mathrm{Kp}=1$ (low activ- ity), $\mathrm{Kp}=2$ (moderate activity), and $\mathrm{Kp} \geq 3$ (strong activity) during the period from 01 November to 29 February. Based on these thresholds, we combine the diurnal and monthly SuperDARN-PMSE occurrence probability rate from 1998 - 2007, as shown in Fig. 8.

In Fig. 8a, when $\mathrm{Kp}=0$, the diurnal and monthly SuperDARN-PMSE occurrence rate is shown. There is a high probability of the SuperDARN-PMSE occurrence during the summer months, with a value of $\sim 45 \%$. At $\mathrm{Kp} \leq 2$ (Figs. $8 \mathrm{~b}$ and c), the SuperDARN-PMSE occurrence probability rates decrease to about $35 \%$. We continue to observe reduction in SuperDARN-PMSE occurrence probability rate at $\mathrm{Kp} \geq 3$ (Fig. 8d) with about $10 \%$.

We found a significant correlation between the SuperDARN-PMSE occurrence probability rate and Kp index for the years 1998 - 2007 summers. The higher SuperDARNPMSE rates were obtained during lower geomagnetic activity and lower during a high geomagnetic condition. This might partly be the result of a polar hole near the SANAE IV aurora location and/or due to strong activity associated with auroral substorms (Crowley et al. 1993).

The polar cusp is the region where the solar wind gains direct entry to the magnetosphere, regardless of the physical processes in the interaction between the solar wind and the geomagnetic field. The intersection region of the cusp with the polar ionosphere and atmosphere is normally located at higher geomagnetic latitude, which is the SANAE IV geomagnetic FOV region (Fig. 1), near the local sector of the auroral oval. It is well known that the intensity 
of auroral displays or precipitation in the auroral oval can be determined based on the geomagnetic conditions. In the proximity of the auroral oval, there is an enhanced ionospheric heating due to precipitating particles causing the SuperDARN-PMSE intensity to decrease with the electron temperature rising. This partly corroborates the Zhongshan radar observation (Liu et al. 2013), but the second midnight peak observed by Liu et al. (2013) is not consistent with our predominant diurnal variation. This might be due to complexity in the electrodynamic coupling between the solar wind and the middle atmosphere, which has been the exigent scientific challenge in the study of solar terrestrial interaction and atmospheric physics. Note that in this study we consider, primarily, geomagnetic activity. Precipitation due to geomagnetic activity is just a single parameter in a system of multiple variables, an effort is underway to examine the influence of some other parameters such as tides and gravity waves during the SuperDARN-PMSE occurrence.

In the prequel paper (Ogunjobi et al. 2015), we found no significant correlations between SuperDARN-PMSE occurrence rate and absorption. Intuitively, we expect high Kp index to cause robust cosmic noise absorption (Ogunjobi et al. 2014b); hence similar trend in the occurrence rate with $\mathrm{Kp}$ and absorption. Nonetheless, the inconsistency might

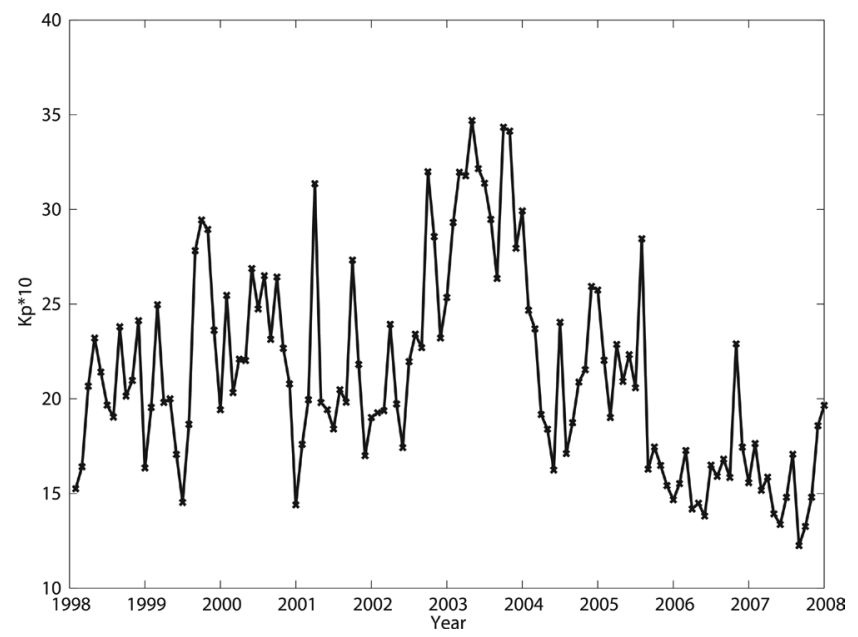

Fig. 7. Monthly averaged Kp index in OMNI format from the years 1998 - 2007.

(a)

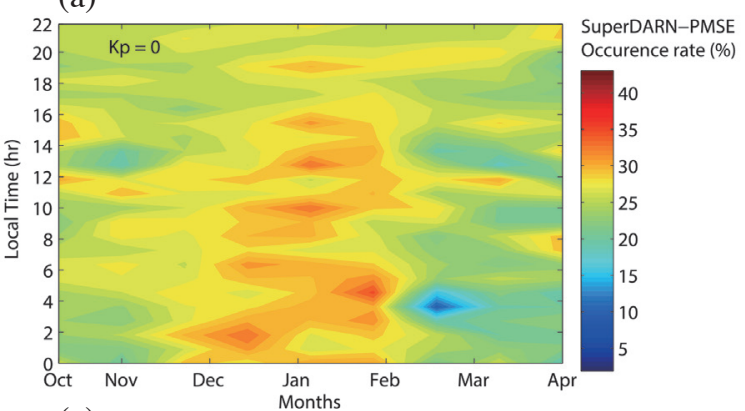

(c)

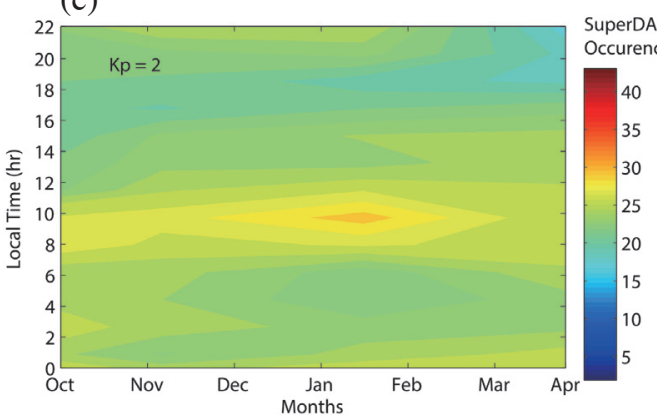

(b)

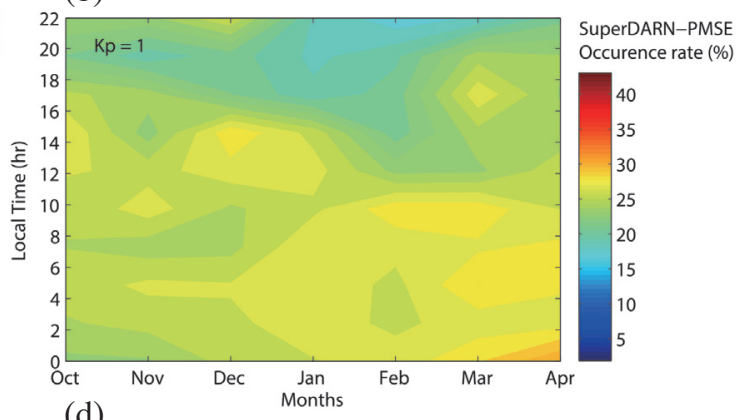

(d)

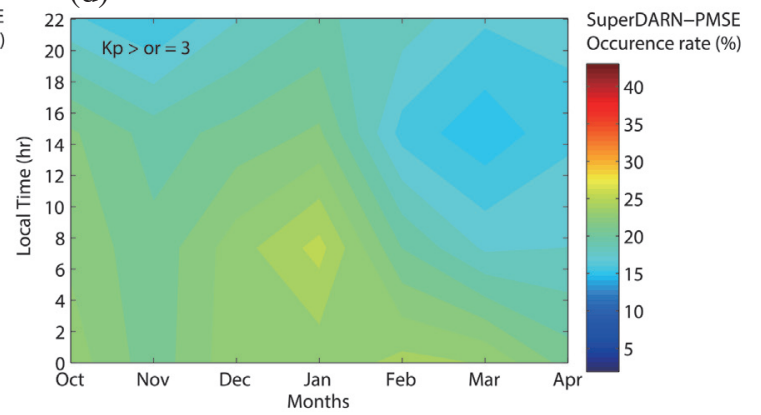

Fig. 8. Diurnal and seasonal contours for SuperDARN-PMSE at different geomagnetic activity levels: (a) Kp = 0, (b) Kp = 1, (c) Kp = 2, and (d) $\mathrm{Kp}=3$ over observational periods. (Color online only) 
be, partly, due to technical approach for obtaining Kp index, radar, and riometer measurements. The $\mathrm{Kp}$ index, for example, is based on global geomagnetic field measurements and thus depends on the electron density above $100 \mathrm{~km}$ (Thomsen 2004), while cosmic noise absorption (as measured by riometer) is determined by height integrated electron density below $100 \mathrm{~km}$ (Clilverd et al.2010). This study, in the context of geomagnetic activity dependence, presents a striking contrast to Bremer et al. (2009). This might be due to the submission of Liu et al. (2013). It was noted that HF radars (used in this study) cannot discriminate the echo height as accurate/correct as the VHF radar (used in Bremer et al. 2009). This is because of the poorer range resolution of HF radar relative to VHF types. Furthermore, SuperDARN HF radar make use of oblique sounding techniques and the echoes include other sources different from ionopshere directly above it, whereas VHF radar receives the echoes from the ionopshere directly above the radar.

\subsection{Mesospheric Temperature and Winds in Relation to SuperDARN-PMSE}

Other factors, which might also induce significant influence on SuperDARN-PMSE occurrence probability rate is the neutral wind forcing, depending on its variability. Since SANAE IV is at near auroral oval location, we may expect neutrals to dominate. The trend of neutrals (neutral winds and neutral temperature) in relation to SuperDARNPMSE season might be significant. Here, we have expanded temperatures observations based on our explanation since Ogunjobi et al. (2015) (Fig. 8 of that paper). Here, we present the average SABER vertical temperature during November, December, January, and March of the possible years from 2002/2003, 2003/2004, 2004/2005, 2005/2006, 2006/2007 Antarctic summers in Fig. 9. It should also be said that it is generally accepted that PMSE are caused by the presence of nanometer-scale ice particles, which modify the plasma of the D-region resulting in backscatter due to neutral air turbulence. Analysis of microphysical parameters of mesospheric ice clouds in relation to PMSE (e.g., Hervig et al. 2009) and the recent Solar Occultation for Ice Experiment (SOFIE) (Hervig et al. 2011), may be a quantitative explanation in this context. Therefore, temperatures observations with SABER in relation to SuperDARN-PMSE can only be qualitative. This is because SABER temperatures are, perhaps, too large to quantitatively explain the existence of SuperDARN-PMSE.

Figures $9 \mathrm{a}-\mathrm{e}$ have the trend of a lowering of mesopause temperature from December until January. These two months represent the relative period of maximum occurrence rate (note that SABER is mostly outside SANAE IV vicinity in February months). In December and January, temperatures decrease to about $150 \mathrm{~K}$ while SuperDARNPMSE rate also increases significantly to about $50 \%$ except for the year 2006 or 2007.

Conversely, we observe a decrease in mesopause temperature in the months of November and March in comparison with SuperDARN-PMSE monthly distribution in Fig. 6, the mesopause temperature during November and March is generally seen to be $>180 \mathrm{~K}$ tied to lower $(\sim 10 \%)$ SuperDARN-PMSE occurrence rate. Perhaps the temperatures in the austral mesosphere are closer to radiative equilibrium. This can only be true if the topography in the troposphere plays an important role (via gravity wave generation) in the mesospheric dynamics due to the orographic terrain in Antarctic (Lübken et al. 2004). Unfortunately, temperature measurements are not available in our region of interest during February when the SuperDARN-PMSE rate gradually decreases. Nevertheless, temperature profiles during March illustrate what should be anticipated as it gets higher than the summer solstice. We expect mesospheric neutral wind flow to shed more light on this aspect.

For completeness, therefore, we extend the meridional and zonal wind observations over SANAE IV in relation to mesospheric temperature variations, which we earlier provided on a short-term scale in Ogunjobi et al. (2015). Present study has expanded on this for the purpose of clarity on the influence of solar activity. Here we obtained radar measurements of mesospheric neutral winds from the years 1998 2007. Note that this is meteor radar wind observation hence the caveat in section 2.2.1 applies. Figure 10 (top panel and bottom) presents contours of all the available monthly-mean winds. There is a data gap in early parts of 1998 and 2007 from SANAE IV SuperDARN radar. This figure shows a clear indication of how the monthly-mean winds vary from year to year. Since the data analysis is based on monthly averages, we might ignore the short periodic waves.

In both meridional (Fig. 10 top) and zonal wind (Fig. 10 bottom), we observe a monthly pattern that repeats from year to year, at least in summer. In this current paper, we observe a special feature of neutral winds, prior to 2003 . Comparison of Fig. 10 and Kp index (Fig. 8) shows that during an enhanced solar activity, energetic particle precipitation as well as levels of extreme ultraviolent (EUV) radiation could be high. Nevertheless, the quiet time electrodynamics of the Mesosphere and Lower Thermosphere (MLT) region might be driven mainly by tides and gravity waves propagating upward from their source regions in the lower atmosphere (Richardson et al. 2001; Ogunjobi et al. 2014b). It can be seen that prior to the start of the SuperDARN-PMSE peaks (November), the mean meridional winds become more positive and the zonal winds also grow significantly. Conversely, we observe a period of equatorward (negative) zonal winds starting from the middle of December to early January while the pole ward meridional winds are decreasing. This period (mid-December to early January) represents the time of high peaks in monthly SuperDARN-PMSE occurrence probability rate (Fig. 6), which give further 
(a)

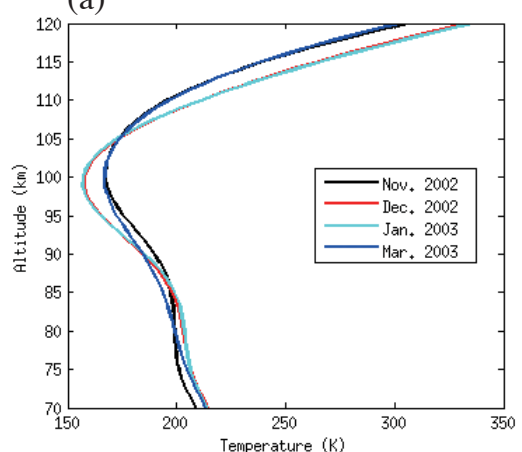

(d)

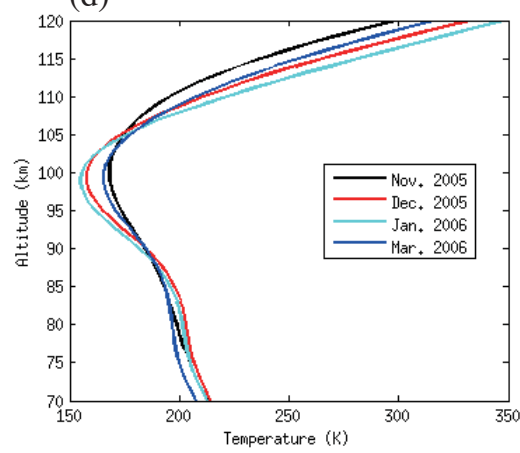

(b)

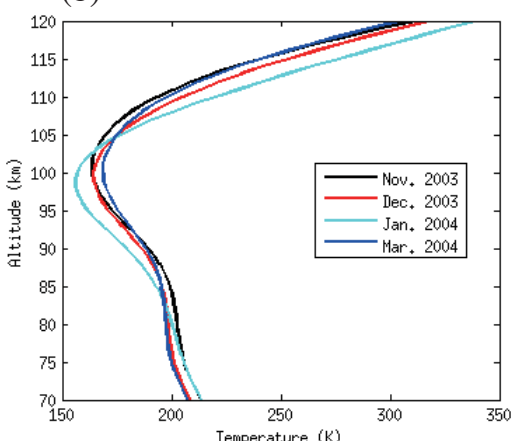

(e)

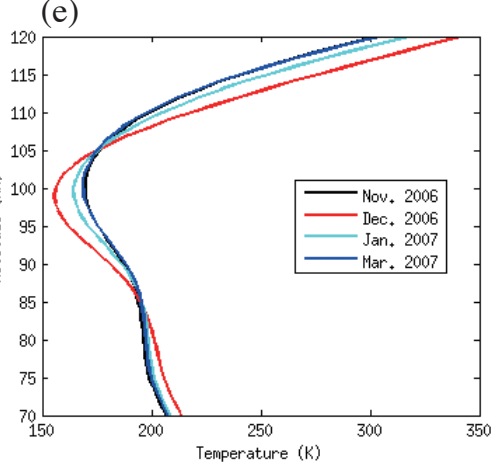

(c)

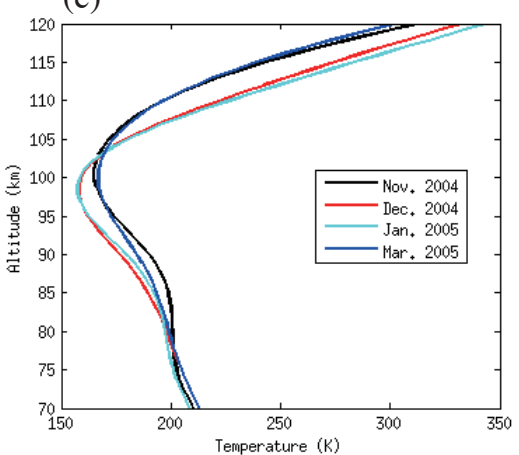

Fig. 9. From (a) - (e), SABER mean temperature pro les from 2002/2003 to 2006/2007 Antarctic summers. The black, red, light green, and blue line represents November, December, January, and March respectively. The measurements are obtained from SABER in the vicinity of SANAE IV Radar site location. (Color online only)
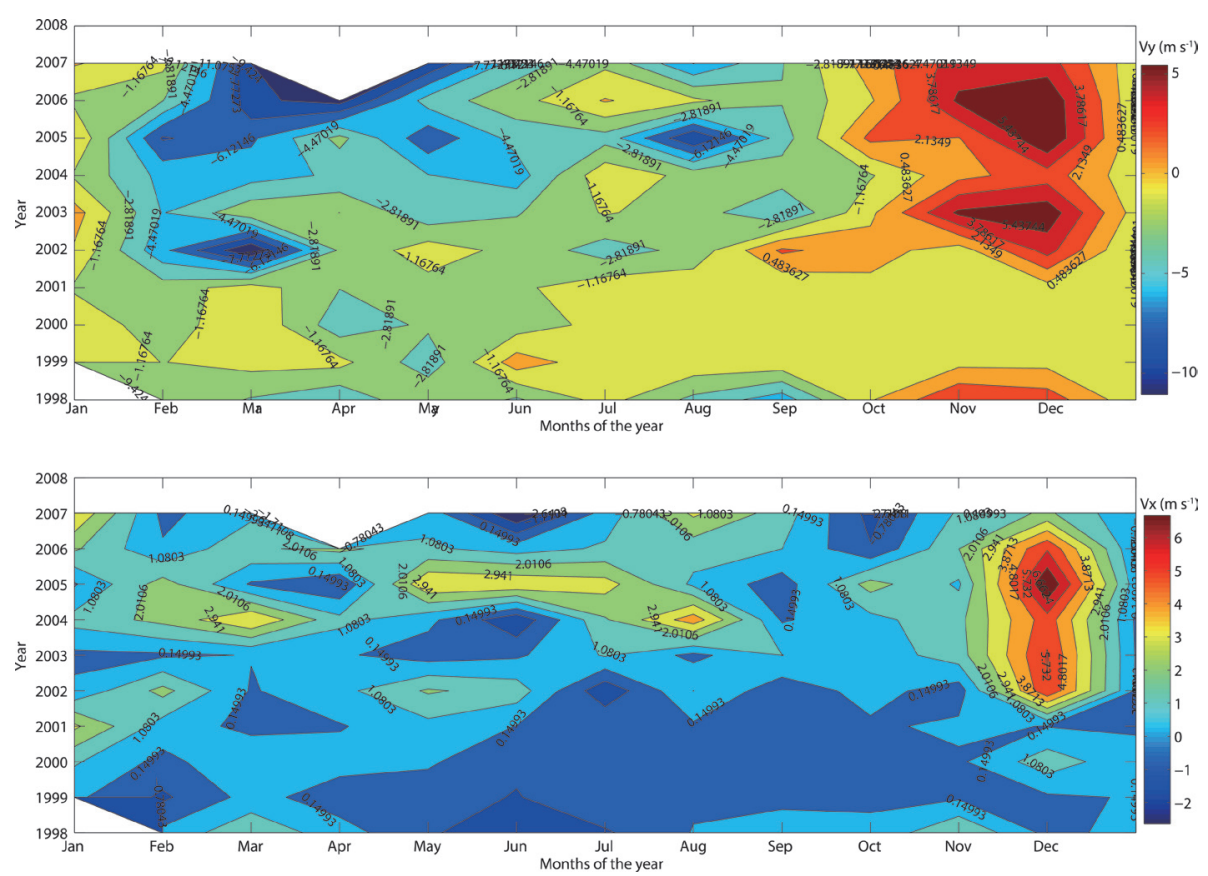

Fig. 10. Seasonal and year-to-year variations of meridional (top) and zonal (bottom) mean winds from the years 1998 - 2007. (Color online only) 
evidence on the role of mesospheric transport circulation in SuperDARN-PMSE generation, as discussed in Fig. 9 of our prequel paper (Ogunjobi et al. 2015). It is generally accepted that the middle atmosphere transport circulation is pole to pole with a rising motion in the summer hemisphere and the corresponding sinking in the winter hemisphere.

\section{SUMMARY AND CONCLUSION}

We examined SuperDARN-PMSE from SuperDARN SANAE IV HF radar in relation to geomagnetic activity. We presented several SuperDARN-PMSE characteristics based on the nine (1998/1999 - 2006/2007) PMSE seasons. Variables sorted for includes diurnal variation, monthly variation, mesospheric temperature, and winds variation. The major characteristics noted are as follows:

(1) Similar to previous observations, SuperDARN-PMSE monthly rate is enhanced at the beginning of December summer, remains at the highest level until several days after the summer solstice and then gradually decreases towards the end of February every year. The SuperDARN-PMSE occurrence rate show diurnal variations with broader maxima from $11-13$ LT and minima between 20 - 22 LT. No significant year-to-year variation is found in the diurnal SuperDARN-PMSE occurrence rate. The SuperDARN-PMSE peaks corroborates the previous suggestion on the influence of pole-to-pole mesospheric transport circulations in SuperDARN-PMSE generation.

(2) The difference in the SuperDARN-PMSE occurrence rate is significant for different geomagnetic activity, $\mathrm{Kp}$, levels. We observed significant influence of enhanced magnetospheric convection on SuperDARN-PMSE occurrence probability rate. When $\mathrm{Kp}=0$, we obtained $\sim 45 \%$ of SuperDARN-PMSE occurrence rate. At Kp $\leq 2$, SuperDARN-PMSE occurrence probability rate reduces to about $35 \%$. We continue to observe lowering of SuperDARN-PMSE at Kp $\geq 3$ with over $10 \%$ lower occurrence probability rate relative to quiet time. This is probably due to the SANAE IV location. In the proximity of the auroral oval, ionospheric electrons increases with the heat of precipitating particles due to geomagnetic storm causing the SuperDARN-PMSE intensity to decrease with the rising electron temperature. In addition, at high-latitudes, the ionisation of the MLT is mainly ascribable to the Lyman $\alpha$ radiation and magnetospheric particles precipitation; we suggest that a superposition of both ionisation sources might be a likely explanation for fast reduction of SuperDARN-PMSE rates at higher Kp index.

Acknowledgements The authors express thanks for the support of South Africa National Antarctic Program (SANAP) and logistics of South Africa National Space Agency (SANSA) in providing SANAE IV riometer data. SANAP,
SANSA and HF radar group, University of KwaZulu-Natal, support the SANAE IV HF radar. The SuperDARN radar wind data were provided by the British Antarctic Survey at http://psddb.nerc-bas.ac.uk. Research is funded by the North-West University Research Fellow grant.

\section{REFERENCES}

Balsley, B. B., W. L. Ecklund, and D. C. Fritts, 1983: Mesospheric radar echoes at Poker Flat, Alaska: Evidence for seasonally dependent generation mechanisms. Radio Sci., 18, 1053-1058, doi: 10.1029/RS018i006p01053. [Link]

Brekke, A., 1997: Physics of the Upper Polar Atmosphere, Wiley-Praxis Series in Atmospheric Physics, Wiley, $504 \mathrm{pp}$.

Bremer, J., P. Hoffmann, R. Latteck, W. Singer, and M. Zecha, 2009: Long-term changes of (polar) mesosphere summer echoes. J. Atmos. Sol.-Terr. Phys., 71, 15711576, doi: 10.1016/j.jastp.2009.03.010. [Link]

Chisham, G., M. Lester, S. E. Milan, M. P. Freeman, W. A. Bristow, A. Grocott, K. A. McWilliams, J. M. Ruohoniemi, T. K. Yeoman, P. L. Dyson, R. A. Greenwald, T. Kikuchi, M. Pinnock, J. P. S. Rash, N. Sato, G. J. Sofko, J. P. Villain, and A. D. M. Walker, 2007: A decade of the Super Dual Auroral Radar Network (SuperDARN): Scientific achievements, new techniques and future directions. Surv. Geophys., 28, 33-109, doi: 10.1007/s10712-007-9017-8. [Link]

Cho, J. Y. N. and J. Röttger, 1997: An updated review of polar mesosphere summer echoes: Observation, theory, and their relationship to noctilucent clouds and subvisible aerosols. J. Geophys. Res., 102, 2001-2020, doi: 10.1029/96JD02030. [Link]

Clilverd, M. A., C. J. Rodger, R. J. Gamble, T. Ulich, T. Raita, A. Seppälä, J. C. Green, N. R. Thomson, J. A. Sauvaud, and M. Parrot, 2010: Ground-based estimates of outer radiation belt energetic electron precipitation fluxes into the atmosphere. J. Geophys. Res., 115, A12304, doi: 10.1029/2010JA015638. [Link]

Codrescu, M. V., T. J. Fuller-Rowell, R. G. Roble, and D. S. Evans, 1997: Medium energy particle precipitation influences on the mesosphere and lower thermosphere. J. Geophys. Res., 102, 19977-19987, doi: 10.1029/97JA01728. [Link]

Crowley, G., H. C. Carlson, S. Basu, W. F. Denig, J. Buchau, and B. W. Reinisch, 1993: The dynamic ionospheric polar hole. Radio Sci., 28, 401-413, doi: 10.1029/92RS02878. [Link]

De Abreu, A. J., P. R. Fagundes, Y. Sahai, R. de Jesus, J. A. Bittencourt, C. Brunini, M. Gende, V. G. Pillat, W. L. C. Lima, J. R. Abalde, and A. A. Pimenta, 2010: Hemispheric asymmetries in the ionospheric response observed in the American sector during an intense 
geomagnetic storm. J. Geophys. Res., 115, A12312, doi: 10.1029/2010JA015661. [Link]

Ecklund, W. L. and B. B. Balsley, 1981: Long-term observations of the Arctic mesosphere with the MST radar at Poker Flat, Alaska. J. Geophys. Res., 86, 7775-7780, doi: 10.1029/JA086iA09p07775. [Link]

Greenwald, R. A., K. B. Baker, J. R. Dudeney, M. Pinnock, T. B. Jones, E. C. Thomas, J. P. Villain, J. C. Cerisier, C. Senior, C. Hanuise, R. D. Hunsucker, G. Sofko, J. Koehler, E. Nielsen, R. Pellinen, A. D. M. Walker, N. Sato, and H. Yamagishi, 1995: DARN/SuperDARN: A global view of the dynamics of high-latitude convection. Space Sci. Rev., 71, 761-796, doi: 10.1007/ BF00751350. [Link]

Hervig, M. E., L. L. Gordley, J. M. Russell III, and S. M. Bailey, 2009: SOFIE PMC observations during the northern summer of 2007. J. Atmos. Sol.-Terr. Phys., 71, 331-339, doi: 10.1016/j.jastp.2008.08.010. [Link]

Hervig, M. E., M. Rapp, R. Latteck, and L. L. Gordley, 2011: Observations of mesospheric ice particles from the ALWIN radar and SOFIE. J. Atmos. Sol.-Terr. Phys., 73, 2176-2183, doi: 10.1016/j.jastp.2010.08.002. [Link]

Hoffmann, P., W. Singer, and J. Bremer, 1999: Mean seasonal and diurnal variations of PMSE and winds from 4 years of radar observations at ALOMAR. Geophys. Res.Lett.,26,1525-1528,doi: 10.1029/1999GL900279. [Link]

Hosokawa, K., T. Ogawa, N. F. Arnold, M. Lester, N. Sato, and A. S. Yukimatu, 2005: Extraction of polar mesosphere summerechoes from SuperDARN data.Geophys. Res. Lett., 32, L12801, doi: 10.1029/2005GL022788. [Link]

Hussey, G. C., C. E. Meek, D. André, A. H. Manson, G. J. Sofko, and C. M. Hall, 2000: A comparison of northern hemisphere winds using SuperDARN meteor trail and MF radar wind measurements. J. Geophys. Res., 105, 18053-18066, doi: 10.1029/2000JD900272. [Link]

Kirkwood, S., 1993: Modelling the undisturbed highlatitude E region. Adv. Space Res., 13, 101-104, doi: 10.1016/0273-1177(93)90258-D. [Link]

Klekociuk, A. R., R. J. Morris, and J. L. Innis, 2008: First Southern Hemisphere common-volume measurements of PMC and PMSE. Geophys. Res. Lett., 35, L24804, doi: 10.1029/2008GL035988. [Link]

Klostermeyer, J., 1999: On the diurnal variation of polar mesosphere summer echoes. Geophys. Res. Lett., 26, 3301-3304, doi: 10.1029/1999GL003629. [Link]

Latteck, R., W. Singer, R. J. Morris, D. A. Holdsworth, and D. J. Murphy, 2007: Observation of polar mesosphere summer echoes with calibrated VHF radars at $69^{\circ}$ in the Northern and Southern hemispheres. Geophys. Res. Lett., 34, L14805, doi: 10.1029/2007GL030032. [Link]

Lester, M., 2013: The Super Dual Auroral Radar Net- work (SuperDARN): An overview of its development and science. Adv. Polar Sci., 24, 1-11, doi: 10.3724/ SP.J.1085.2013.00001. [Link]

Liu, E. X., H. Q. Hu, K. Hosokawa, R. Y. Liu, Z. S. Wu, and Z. Y. Xing, 2013: First observations of polar mesosphere summer echoes by SuperDARN Zhongshan radar. J. Atmos. Sol.-Terr. Phys., 104, 39-44, doi: 10.1016/j.jastp.2013.07.011. [Link]

Lübken, F. J., A. Müllemann, and M. J. Jarvis, 2004: Temperatures and horizontal winds in the Antarctic summer mesosphere. J. Geophys. Res., 109, D24112, doi: 10.1029/2004JD005133. [Link]

Morris, R. J., M. B. Terkildsen, D. A. Holdsworth, and M. R. Hyde, 2005: Is there a causal relationship between cosmic noise absorption and PMSE? Geophys. Res. Lett., 32, L24809, doi: 10.1029/2005GL024568. [Link]

Nilsson, H., S. Kirkwood, R. J. Morris, R. Latteck, A. R. Klekociuk, D. J. Murphy, M. Zecha, and E. Belova, 2008: Simultaneous observations of Polar Mesosphere Summer Echoes at two different latitudes in Antarctica. Ann. Geophys., 26, 3783-3792, doi: 10.5194/angeo-26-3783-2008. [Link]

Ogawa, T., S. Nozawa, M. Tsutsumi, N. F. Arnold, N. Nishitani, N. Sato, and A. S. Yukimatu, 2004: Arctic and Antarctic polar mesosphere summer echoes observed with oblique incidence HF radars: Analysis using simultaneous MF and VHF radar data. Ann. Geophys., 22, 40494059, doi: 10.5194/angeo-22-4049-2004. [Link]

Ogunjobi, O., V. Sivakumar, and N. Mbatha, 2014a: A case study of energy deposition and absorption by magnetic cloud electrons and protons over the high latitude stations: Effects on the mesosphere and lower thermosphere. Terr. Atmos. Ocean. Sci., 25, 219-232, doi: 10.3319/TAO.2013.10.14.01(AA). [Link]

Ogunjobi, O., V. Sivakumar, and W. T. Sivla, 2014b: A superposed epoch study of the effects of solar wind stream interface events on the upper mesospheric and lower thermospheric temperature. Adv. Space Res., 54, 1732-1742, doi: 10.1016/j.asr.2014.07.005. [Link]

Ogunjobi, O., V. Sivakumar, J. A. E. Stephenson, and W. T. Sivla, 2015: Evidence of polar mesosphere summer echoes observed by SuperDARN SANAE HF radar in Antarctica. Terr. Atmos. Ocean. Sci., 26, 431-440, doi: 10.3319/TAO.2015.03.06.01(AA). [Link]

Palmer, J. R., H. Rishbeth, G. O. L. Jones, and P. J. S. Williams, 1996: A statistical study of polar mesosphere summer echoes observed by EISCAT. J. Atmos. Terr. Phys., 58, 307-315, doi: 10.1016/0021-9169(95)000380 . [Link]

Rapp, M. and F. J. Lübken, 2004: Polar mesosphere summer echoes (PMSE): Review of observations and current understanding. Atmos. Chem. Phys., 4, 2601-2633, doi: 10.5194/acpd-4-4777-2004. [Link]

Richardson, I. G., E. W. Cliver, and H. V. Cane, 2001: 
Sources of geomagnetic storms for solar minimum and maximum conditions during 1972-2000. Geophys. Res. Lett., 28, 2569-2572, doi: 10.1029/2001GL013052. [Link]

Smirnova, M., E. Belova, S. Kirkwood, and N. Mitchell, 2010: Polar mesosphere summer echoes with ESRAD, Kiruna, Sweden: Variations and trends over 19972008. J. Atmos. Sol.-Terr. Phys., 72, 435-447, doi: 10.1016/j.jastp.2009.12.014. [Link]

Thomsen, M. F., 2004: Why $K p$ is such a good measure of magnetospheric convection. Space Weather, 2, S11004, doi: 10.1029/2004SW000089. [Link]

Tsunoda, R. T., 1988: High-latitude $F$ region irregularities: A review and synthesis. Rev. Geophys., 26, 719-760, doi: 10.1029/RG026i004p00719. [Link]

Villain, J. P., R. André, M. Pinnock, R. A. Greenwald, and
C. Hanuise, 2002: A Statistical study of the Doppler spectral width of high-latitude ionospheric F-region echoes recorded with SuperDARN coherent HF radars. Ann. Geophys., 20, 1769-1781, doi: 10.5194/angeo-20-1769-2002. [Link]

Yukimatu, A. S. and M. Tsutsumi, 2002: A new superDARN meteor wind measurement: Raw time series analysis method and its application to mesopause region dynamics. Geophys. Res. Lett., 29, doi: 10.1029/2002GL015210. [Link]

Yukimatu, A. S. and M. Tsutsumi, 2003: Correction to "A new SuperDARN meteor wind measurement: Raw time series analysis method and its application to mesopause region dynamics" by Akira Sessai Yukimatu and Masaki Tsutsumi. Geophys. Res. Lett., 30, doi: 10.1029/2002GL016560. [Link] 